Research Article

\title{
Simulation Analysis and Experimental Study on the Working State of Sinking Headframe in the Large Underground Shaft
}

\author{
Yin Qixiang $\mathbb{D}^{1},{ }^{1}$ Zhao Weiping $\mathbb{D}^{2}{ }^{2}$ Xin Wen, ${ }^{2}$ Yang Hailin, ${ }^{2}$ and Zhang Linglei ${ }^{1}$ \\ ${ }^{1}$ Jiangsu Vocational Institute of Architectural Technology, Xuzhou, Jiangsu 221116, China \\ ${ }^{2}$ Tangshan Polytechnic College, Tangshan, Hebei 063299, China \\ Correspondence should be addressed to Zhao Weiping; zhaowphj@163.com
}

Received 26 January 2021; Revised 25 March 2021; Accepted 7 May 2021; Published 18 May 2021

Academic Editor: Jia Lin

Copyright (c) 2021 Yin Qixiang et al. This is an open access article distributed under the Creative Commons Attribution License, which permits unrestricted use, distribution, and reproduction in any medium, provided the original work is properly cited.

Based on the newly developed sinking headframe for the deep and large shaft, the finite element model of the full-scale headframe was established by using SAP2000. Through the calculation, the theoretical stress of the headframe at sinking depths of $40 \mathrm{~m}$, $143 \mathrm{~m}, 223 \mathrm{~m}, 518 \mathrm{~m}, 762 \mathrm{~m}, 1000 \mathrm{~m}, 1250 \mathrm{~m}$, and $1503 \mathrm{~m}$ was obtained and then compared with the field measured stress. The results show that with the increase of shaft sinking depth, the theoretical stress of finite element simulation and the field measured stress of each member of the sheave wheel platform and the headframe increase linearly, and for the maximum member stress in the upper, middle, and lower layers of the headframe, the numerical simulation value is greater than the field measured value and less than the designed steel strength. In other words, under normal working conditions, headframe members are in the elastic stress stage and meet the design requirements, and instability failure of headframe members will not occur. The end-restraint mode of the supporting bars has a great influence on the force of the top member. The reasonable selection of the restraint mode in the simulation is the key to the accuracy of the calculation results. The simulation results well reflect the actual stress of the headframe and provide a reliable guarantee for the follow-up work of the project.

\section{Introduction}

China has one of the richest coal reserves in the world. According to incomplete statistics, China's proven coal reserves are about 1 trillion tons, with complete coal types and wide distribution areas, which provides a reliable material guarantee for the development of the coal industry [1-5]. With the mining of mineral resources gradually shifting to the deep, the proportion of large diameter (more than $8 \mathrm{~m}$ ) and deep shaft (more than $1000 \mathrm{~m}$ ) exploitation will be further increased. In mine construction, the shaft construction is generally regarded as the key project, and the sinking headframe is the main stress component in the shaft construction process [6-9]. In the actual construction, the sinking headframe in the large shaft is subject to extremely complex stress, and its bearing capacity not only depends on its own structure but also closely related to the layout of the shaft sinking equipment and the ground winch lifting equipment [10-12]. The reason and limit value of derrick inclination are determined by experiment and finite element modeling analysis. The inclination of derrick, support settlement, and corrosion of support beam are measured by experiment, and the bearing capacity is analyzed by considering defects in the finite element model [13-15].

With the development of test and analysis technology, field tests of prototype structure can be used to verify and develop the calculation theory and then directly applied to production practice to solve problems. More importantly, tracking and monitoring, fault alarm, and automatic control of important buildings are realized to ensure safe operation [16-18]. Due to the limitation of funds and conditions, it is impossible to monitor a large number of structures. Within the operation of structure for a certain time, field tests can be used to detect or diagnose the fault to achieve the purpose of troubleshooting [19-22]. Only through the field test of the prototype structure, various kinds of structural parameters, boundary conditions, and load distribution rules in line with the actual situation and the satisfactory results of the 
theoretical analysis can be obtained. The field test is also the best way to develop the theory of prototype structure testing [23-25]. In a word, field tests and the monitoring of prototype structure play an irreplaceable role in both the theory development and the solution of practical production and scientific research problems [26, 27].

Kong [28] simulated and analyzed the structural changes of the headframe after lifting in the main and auxiliary shafts through the finite element analysis software and improved the stress state of some components of the headframe close to the critical stress state. Xiao et al. [29] used the anchoring agent, screw-thread steel, and concrete foundation reinforcement methods to reinforce the headframe leg foundation. As a result, the further settlement deviation of the headframe foundation was prevented after the use of the freezing method in a mine, and the construction safety and smooth sinking construction were ensured. In previous studies [30-33], the headframe stress caused by headframe deflection was analyzed. Gusella et al. [34] studied the dynamic characteristics of headframe structure and determined its influencing factors based on the simulation analysis. Link [35] regarded the element stiffness parameter as a modified parameter in the process of relevant research and modified the design scheme appropriately based on the obtained results. In these studies [36, 37], the fatigue stress and deformation of various components of headframe were intuitively and comprehensively analyzed based on the field measurement method $[38,39]$.

With the continuous increase of energy demand, the required sinking speed and production efficiency have been improved, and the diameter and depth of the construction shaft have been increased; thus, the lifting capacity of the headframe should be increased greatly. However, the conventional sinking headframe cannot meet the needs of deep and large shaft construction, and the stress analysis of the super large shaft headframe is rarely reported. In this study, the stress of the large sinking headframe developed for the auxiliary shaft (net diameter $10 \mathrm{~m}$, depth $1503.9 \mathrm{~m}$ ) in the Sishanling iron mine was comprehensively analyzed.

\section{Selection of the Headframe for Large Shaft Sinking}

The auxiliary shaft of the Sishanling iron mine was located in Benxi City, Liaoning Province. The net diameter of the shaft was $10.0 \mathrm{~m}$, and the shaft neck section was $40 \mathrm{~m}$ in total. The temporary lock section was $3.7 \mathrm{~m}$, which was supported by $1000 \mathrm{~mm}$ thick brick. The neck section of the shaft was supported by $1000 \mathrm{~mm}$ thick reinforced concrete. The shaft sinking equipment included the lifting system, transportation system, ventilation system, air pressure system, drainage system, and water supply system.

For the engineering conditions of the shaft with a diameter over $8 \mathrm{~m}$ and a depth over $1000 \mathrm{~m}$, the existing $\mathrm{V}$-type headframe with the largest specification cannot meet the construction conditions. According to the construction requirements of drilling equipment and the large shaft, the SA-III type headframe was selected. This headframe was developed by China University of Mining and Technology and Handan Design Engineering China Coal Co., Ltd. meet the development trend of overdepth and large-diameter shaft in China. The Q345 steel was selected as the main and auxiliary materials of the large-scale sinking headframe. Figure 1 shows its structural form, and Figure 2 shows the sinking headframe in working condition.

According to the characteristics of large diameter and deep depth of the auxiliary shaft in Sishanling iron mine and the construction technology of the shaft, the shaft sinking equipment included a hoist and bucket, a $\Phi 9800 \mathrm{~mm}$ threelayer hanging plate, the YSJZ-6.12 hydraulic umbrella drill, and two HZ-6B central rotary rock grabs. According to the selected drilling equipment, eight kinds of drilling depth were obtained: $40 \mathrm{~m}, 143 \mathrm{~m}, 223 \mathrm{~m}, 518 \mathrm{~m}, 762 \mathrm{~m}, 1000 \mathrm{~m}$, $1250 \mathrm{~m}$, and $1503 \mathrm{~m}$; then, the working loads of wire rope of sinking equipment under eight working conditions were obtained. The loads of wire rope were transmitted to the sheave wheel platform and then to the stress bars of the headframe. Figure 3 shows the number and corresponding position of the stress bars.

A FBD-2 $\times 55 \mathrm{~kW}$ counter rotating fan with a $\Phi$ $1000 \mathrm{~mm}$ FRP air duct is installed near the wellhead for forced ventilation. Two $35 \mathrm{~W} \times 7-\Phi 42-1960$ steel wire ropes and two JZ-40/1800 stable car suspensions are selected. A $\Phi 57 \times 3.5$ water supply pipe is arranged in the shaft, and the surface is connected with the underground reservoir. A pressure reducing valve is installed in the water supply pipe in the shaft to meet the water pressure requirements of the rock drill.

\section{Simulation Analysis of Working State of the Large Sinking Headframe}

In the SAP2000 finite element numerical simulation analysis, the number and position of the large sinking headframe were consistent with the measuring points of the headframe, and working conditions of the numerical simulation analysis were consistent with the working condition of the sinking depth measured in the field. The corner columns and supporting bars of large sinking headframe were mainly axial forcebearing bars, and the normal stress at each point on the crosssection was $\sigma=N / A$, and the cross-sections were all $\Phi$ $325 \mathrm{~mm} \times 16 \mathrm{~mm}$. According to the length, these members can be divided into eight types, I-II corner columns and IIIVIII supporting bars. The end spring stiffness of the supporting bars was $1000 \mathrm{~N} / \mathrm{mm}$. Through the force analysis of members and side beam of the sheave wheel platform, the steel of the HN $1350 \mathrm{~mm} \times 600 \mathrm{~mm} \times 25 \mathrm{~mm} \times 45 \mathrm{~mm}$ was adopted for the sheave wheel platform. The calculated length coefficient of the supporting bars was taken as 0.9 , and the calculated length coefficient of the axial compression member hinged at both ends is 1.0. Table 1 provides the parameters of the members.

Through the calculation of $\sigma=N / A$, the stress was obtained. The stress at the sinking depth of $40 \mathrm{~m}$ (the release of the hanging plate) was taken as the reference value in the field measurement. Through the above equations, the theoretical stress of corner column and supporting bars for the 


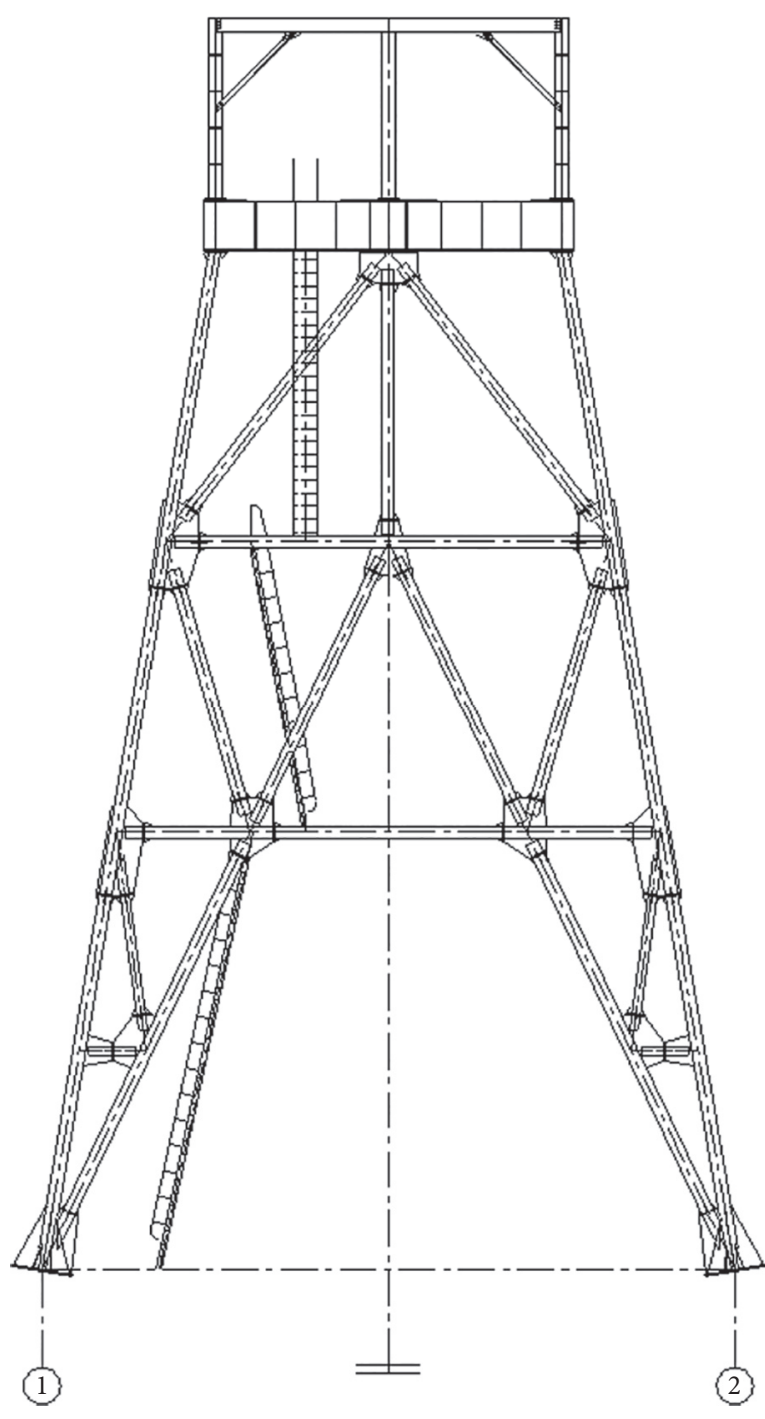

(a)

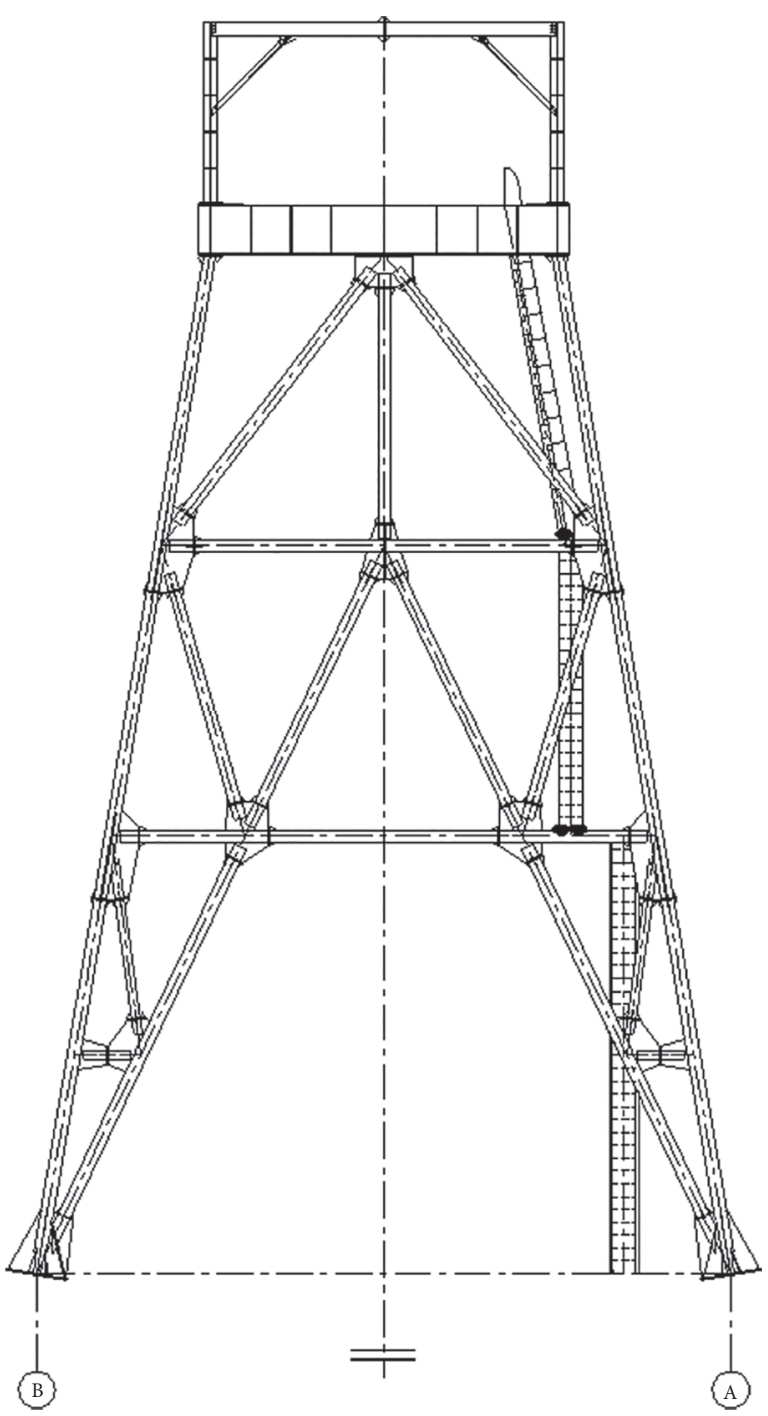

(b)

Figure 1: General drawing of SA-III sinking headframe. (a) Front elevation of headframe. (b) Side elevation of headframe.

headframe in the working condition of $40 \mathrm{~m}, 143 \mathrm{~m}, 223 \mathrm{~m}$, $518 \mathrm{~m}, 762 \mathrm{~m}, 1000 \mathrm{~m}, 1250 \mathrm{~m}$, and $1503 \mathrm{~m}$ was calculated.

3.1. Stress Analysis of Upper Members. With the increase of sinking depth, the theoretical stress curves of the upper corner column and supporting bars are obtained, as shown in Figure 4 and Figure 5, respectively.

As shown in Figures 4 and 5, the stress value of the upper member increases gradually with the increase of sinking depth. The stress growth rate of corner column G07 and supporting bar F17 is the fastest, while that of corner column G04 and supporting bar F01 is the slowest. The reason is that the load growth rate on the beam of the sheave wheel platform corresponding to G07 and F17 is greater than that of G04 and F01. When the sinking depth is $1503 \mathrm{~m}$, the maximum compressive stress of G07 and F17 is $105.4 \mathrm{MPa}$ and $69.7 \mathrm{MPa}$, which is far less than the designed tensile strength of Q345 steel $(f=310 \mathrm{MPa})$. It shows that the upper members are in the elastic stress stage, meeting the design requirements, and the instability failure of headframe members will not occur under the normal working condition within the sinking depth of $1503 \mathrm{~m}$.

3.2. Stress Analysis of Middle Members. With the increase of sinking depth, the theoretical stress curves of the middle corner columns and supporting bars are shown in Figure 6 and Figure 7.

As shown in Figures 6 and 7, the stress value of the middle members gradually increases with the increase of the sinking depth. The growth rate of compressive stress and tensile stress of corner column G08 and supporting bar F22 is the fastest, while that of corner column G05 and supporting bar F06 and supporting bar F04 is the slowest. The reason is that the load growth rate of G08, F22, and F20 corresponding to the sheave platform beam is higher than that of G05, F06, and F04. When the shaft sinking depth is 


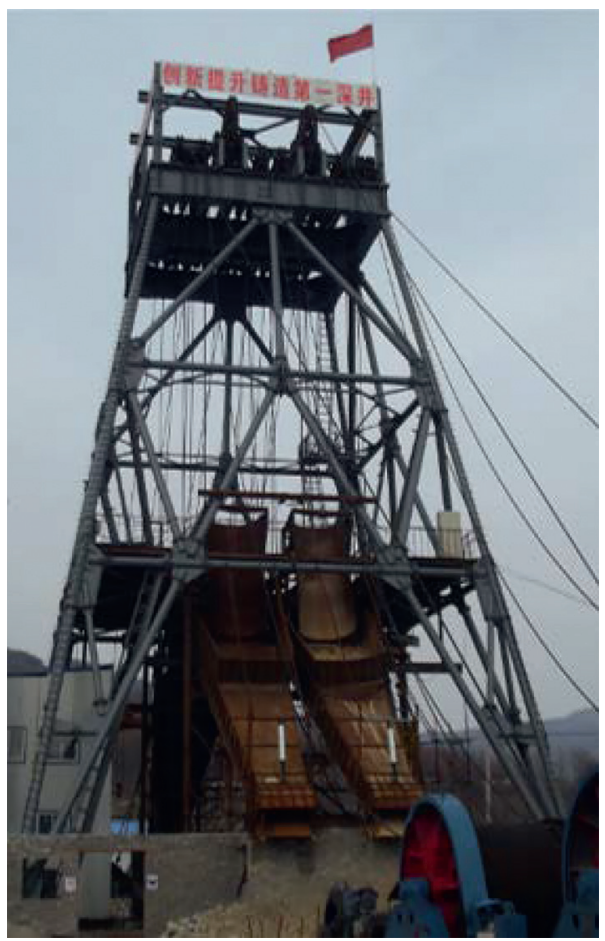

Figure 2: The working condition of sinking headframe in the field.

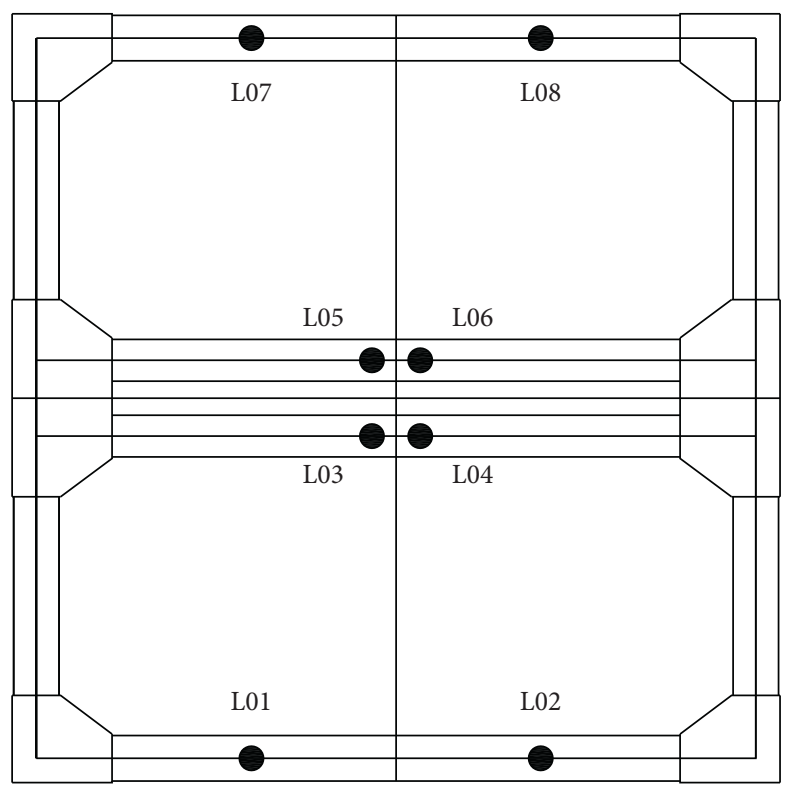

(a)

Figure 3: Continued. 


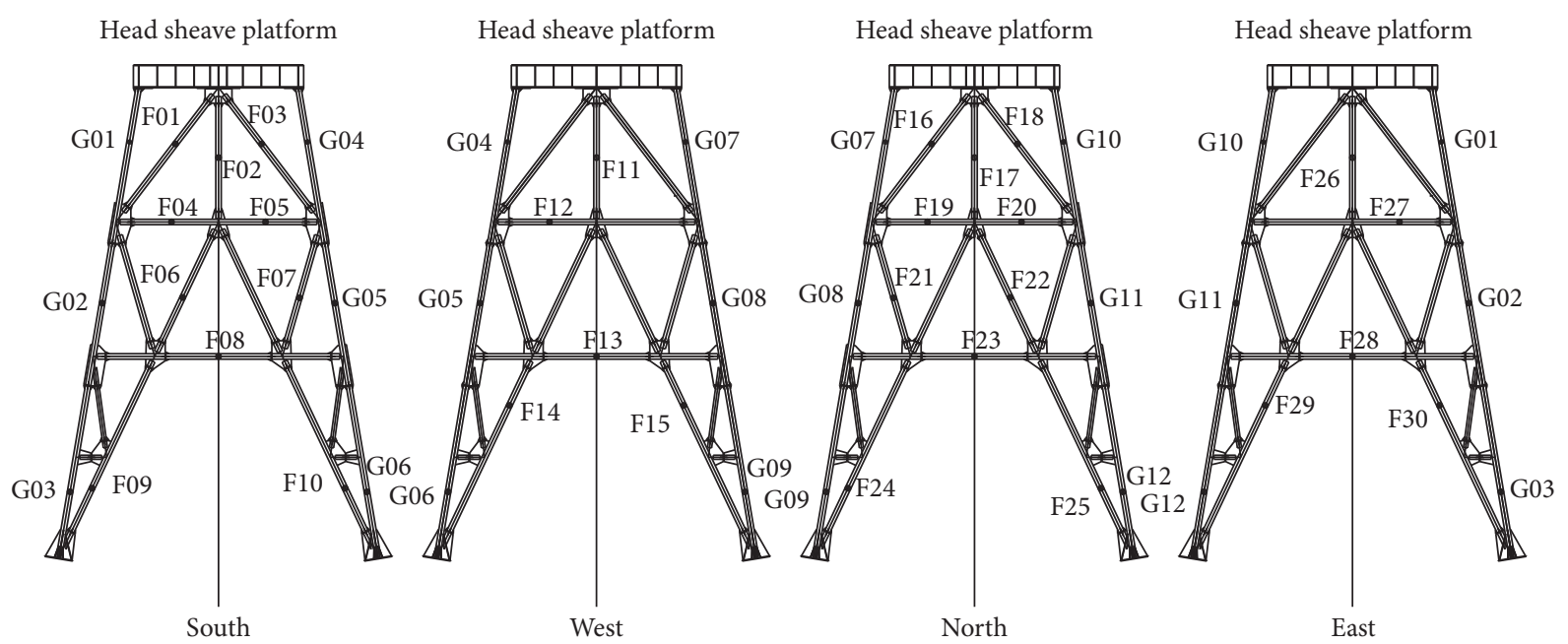

(b)

FIGURE 3: Number and corresponding positions. (a) Sheave wheel platform. (b) Headframe.

TABLE 1: Parameters of the members.

\begin{tabular}{|c|c|c|c|c|c|c|}
\hline Types of member bar & $l / \mathrm{mm}$ & $\mu$ & $I / \mathrm{mm}^{4}$ & $A / \mathrm{mm}^{2}$ & $\lambda$ & Member bar type \\
\hline Class I & 8228.0 & 1.0 & $1.86 \times 10^{8}$ & $1.55 \times 10^{4}$ & 75.2 & Corner columns $01,02,04,05,07,11$ \\
\hline Class II & 6171.0 & 1.0 & $1.86 \times 10^{8}$ & $1.55 \times 10^{4}$ & 56.4 & Corner columns $03,06,09,12$ \\
\hline Class III & 10157.8 & 0.9 & $1.86 \times 10^{8}$ & $1.55 \times 10^{4}$ & 83.6 & Supporting bars F01, F03, F16, F18 \\
\hline Class IV & 8114.8 & 0.9 & $1.86 \times 10^{8}$ & $1.55 \times 10^{4}$ & 66.8 & Supporting bars 02 and 17 \\
\hline Class V & 8962.1 & 0.9 & $1.86 \times 10^{8}$ & $1.55 \times 10^{4}$ & 73.7 & Supporting bars 06 and 21 \\
\hline Class VI & 8436.1 & 0.9 & $1.86 \times 10^{8}$ & $1.55 \times 10^{4}$ & 69.4 & Supporting bars $07, \mathrm{~F} 22$ \\
\hline Class VII & 7608.0 & 0.9 & $1.86 \times 10^{8}$ & $1.55 \times 10^{4}$ & 62.6 & Supporting bars $08,13,23, \mathrm{~F} 28$ \\
\hline Class VIII & 6721.6 & 0.9 & $1.86 \times 10^{8}$ & $1.55 \times 10^{4}$ & 55.3 & Supporting bars $09,10,14,15,24,25,29, \mathrm{~F} 30$ \\
\hline
\end{tabular}

Note. $l$ is the length of the member; $\mu$ is the calculated length; $I$ is the moment of inertia of the section; $A$ is the area of the section; $\lambda$ is the flexibility of the member.

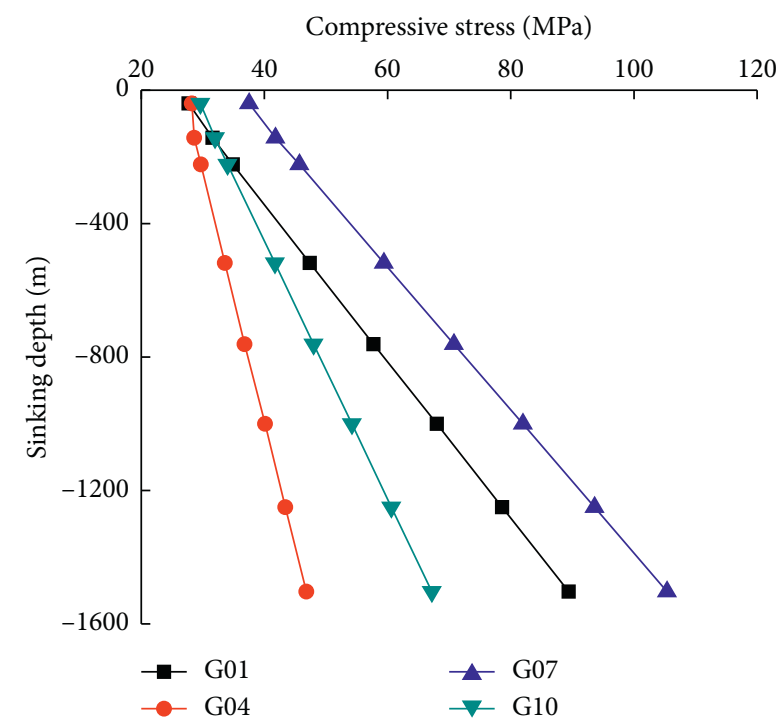

FIGURE 4: Theoretical stress curve of upper corner column under different working conditions.

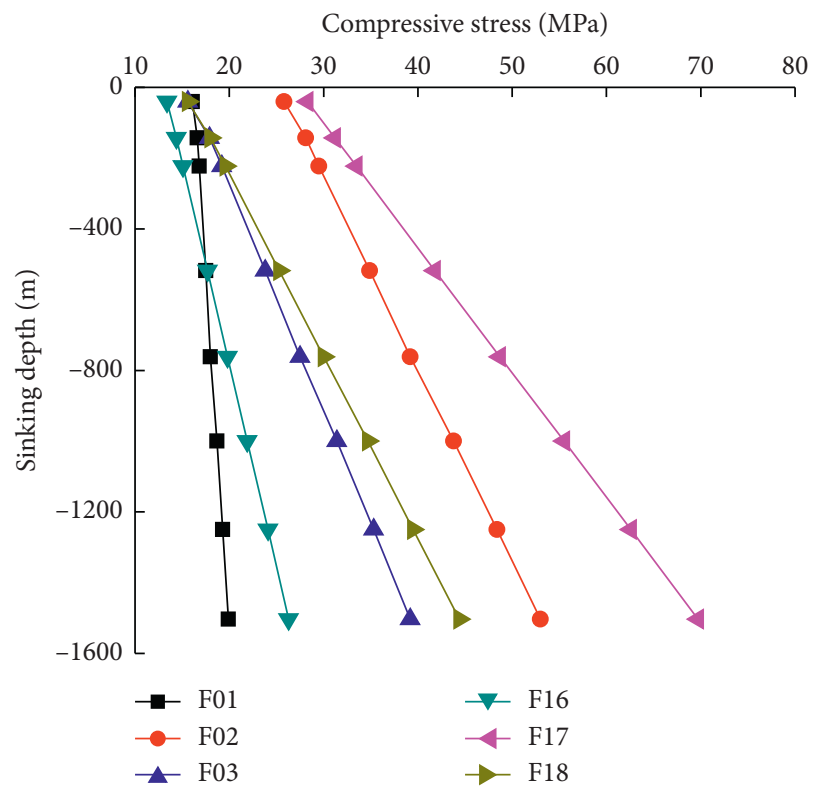

FIGURE 5: Theoretical stress curve of upper supporting bars under different working conditions. 


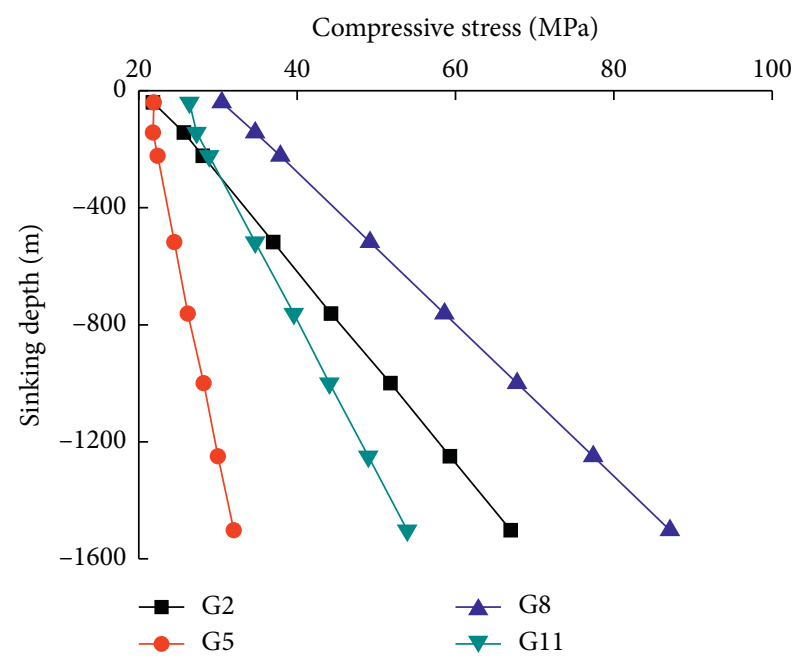

FIGURE 6: The theoretical stress curve of middle corner columns under different working conditions.

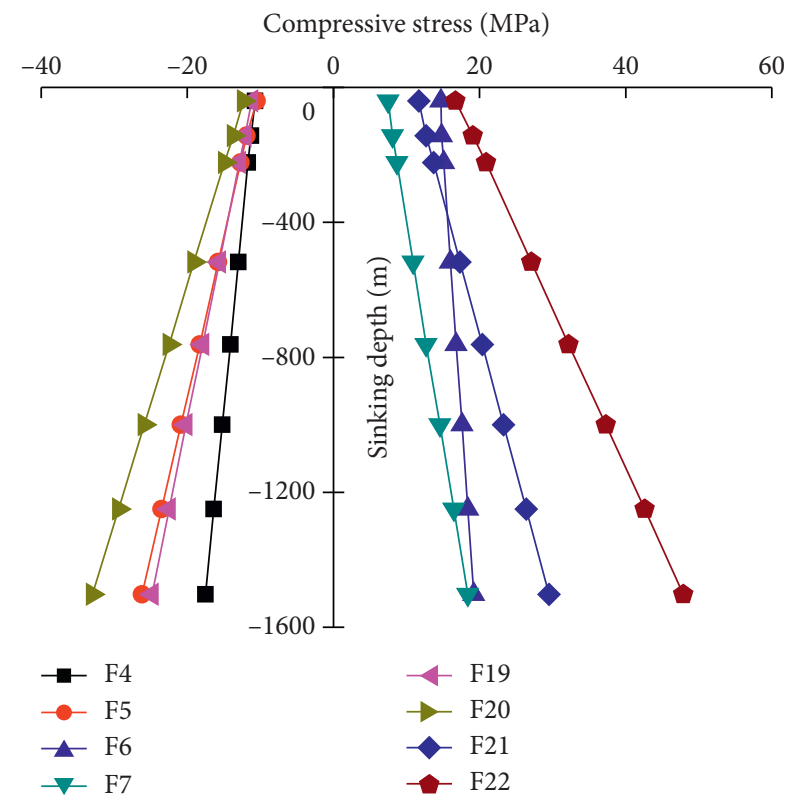

FIgURE 7: The theoretical stress curve of middle supporting bars under different working conditions.

$1503 \mathrm{~m}$, the maximum compressive stress of G08 and F22 are 87.1 $\mathrm{MPa}$ and 47.9 $\mathrm{MPa}$, which is far less than the designed tensile strength of Q345 steel $(f=310 \mathrm{MPa})$. It shows that the middle members are in the elastic stress stage, meeting the design requirements; the instability failure of headframe members will not occur under the normal working condition within the sinking depth of $1503 \mathrm{~m}$.

3.3. Stress Analysis of Lower Members. With the increase of sinking depth, the theoretical stress curve of lower corner columns and supporting bars is obtained, as shown in Figure 8 and Figure 9.

As shown in Figures 8 and 9, the stress value of lower members gradually increases with the increase of the sinking

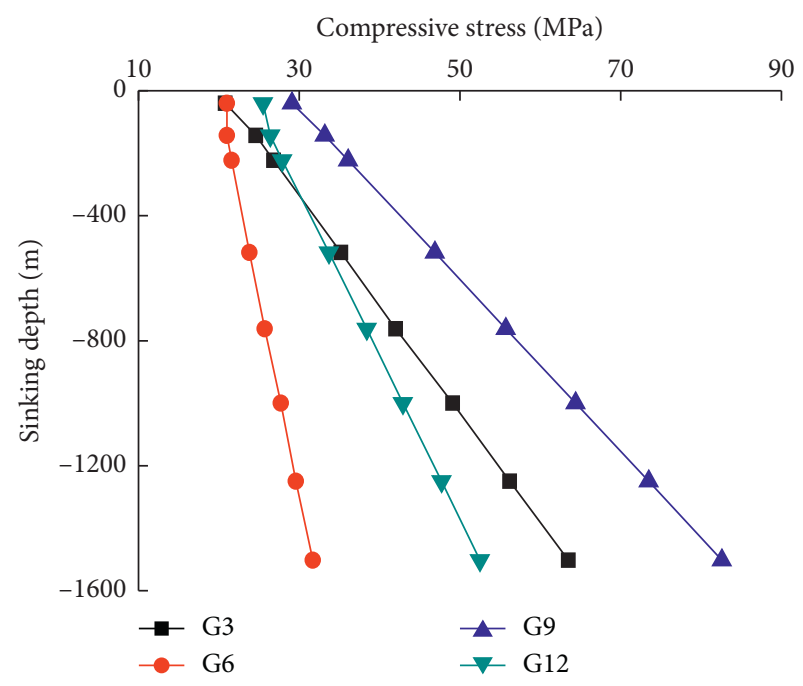

FIgURE 8: Theoretical stress curves of the lower corner column under different working conditions.

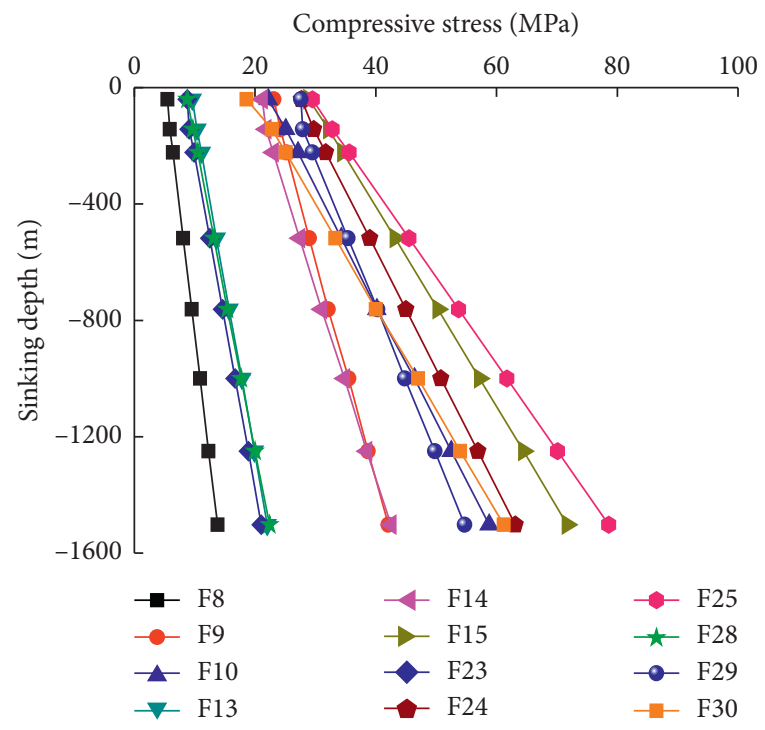

Figure 9: Theoretical stress curves of the lower supporting bars under different working conditions.

depth. The stress growth rate of corner column G09 and supporting bar F25 is the fastest, while that of corner column G06 and support bar F08 is the slowest. When the shaft sinking depth is $1503 \mathrm{~m}$, the maximum compressive stress of G09 and F25 is 82.6 MPa and 78.6 MPa, which is far less than the designed tensile strength of Q345 steel $(f=310 \mathrm{MPa})$. It shows that the top members meet the design requirements and are in the elastic stress stage; the instability failure of headframe members will not occur under the normal working condition within the sinking depth of $1503 \mathrm{~m}$.

3.4. Stress Analysis of Members in the Sheave Wheel Platform. In the establishment process of the finite element model of the sheave wheel platform in the headframe, the bending moment and torque at the end of the supporting member should be 
transferred without the release. The calculation results of the bending normal stress at the measuring points of the crosssection of the sheave wheel platform beam under the wording conditions of $40 \mathrm{~m}, 143 \mathrm{~m}, 223 \mathrm{~m}, 518 \mathrm{~m}, 762 \mathrm{~m}, 1000 \mathrm{~m}$, $1250 \mathrm{~m}$, and $1503 \mathrm{~m}$ are obtained, as shown in Figure 10.

As shown in Figure 10, with the increase of the sinking depth, the theoretical stress of four measuring points L03, L04, 105, and L06 of the two middle beams of the sheave wheel platform and the four measuring points L01, L02, L07, and L08 of the two side beams of the sheave wheel platform in the finite element numerical simulation increases linearly under normal working conditions. When the shaft sinking depth is $1503 \mathrm{~m}$, the maximum stress of the middle beam L05 (L06) of the sheave wheel platform is $34.1 \mathrm{MPa}$, which is far less than the designed tensile strength $(f=310 \mathrm{MPa})$. It shows that the headframe members are in the elastic stress stage, meeting the design requirements, and the instability failure of headframe members will not occur under the normal working condition within the sinking depth of $1503 \mathrm{~m}$.

As shown in Figure 10, the stress growth rate of measuring point L05 (L06) in the middle beam of the sheave wheel platform is the fastest and the largest and that of measuring point L07 in the side beam of the sheave wheel platform is the slowest. Through the analysis of the equipment layout on the beam of the sheave wheel platform in the headframe and the rigid connection at the end of the supporting bar, it can be concluded that there is no support constraint in the middle beam of the sheave wheel platform, and the middle beam is a single span simply supported beam. The load growth rate of measuring points L05 (L06) on the side beam of platform is faster than that of L03 (L04) on the middle beam of platform, and the stress in the midspan increases the fastest and the most. Because of the rigid connection at the end of the supporting bar, the center of the side beam of the platform is supported, so the side beam of the platform can be considered as the two-span continuous beam with a certain supporting function. Since the span is reduced by one time, the stress growth rate at the measuring point of the side beam of the platform is the slowest and the smallest.

\section{Field Measurement and Analysis of the Working State of Sinking Headframe in the Large Shaft}

According to the stress characteristics of the headframe in this project, the constraints of site construction conditions and economic cost and other factors are considered, and the strain gauge electrical measuring system was used as the static test scheme of the headframe working state in this project. According to the basic situation of the auxiliary shaft engineering in Sishanling iron mine, combined with the main test contents of headframe in the SA-III vertical shaft sinking, the main measured headframe strain on-site was

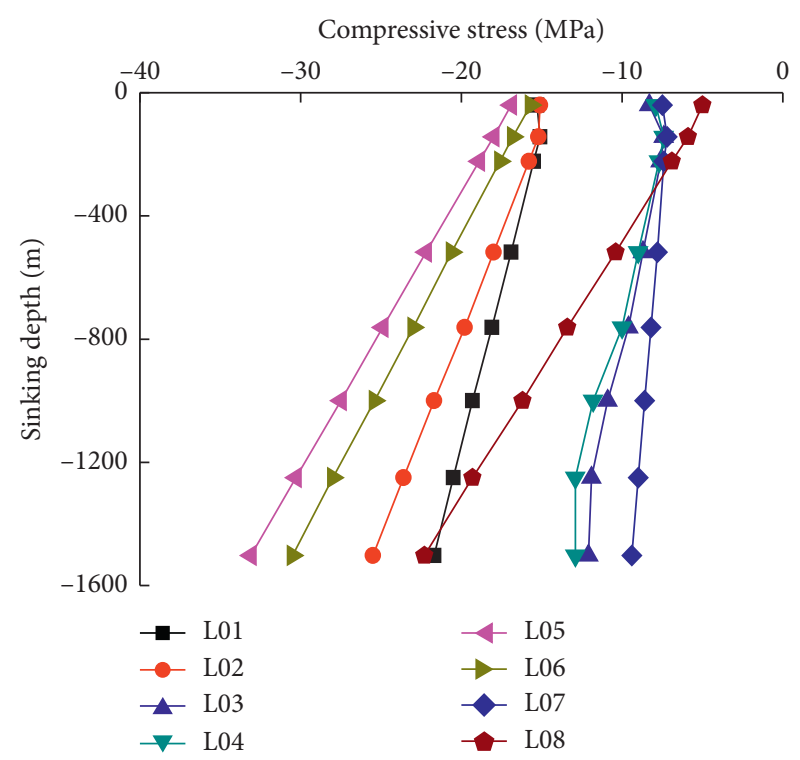

FIgURE 10: Theoretical stress curves of platform beams of sheave wheel platform under different working conditions.

considered, and the actual bearing condition of the headframe was judged, and the datataker test system was adopted.

Eight times of static data acquisition were carried out onsite, including eight working conditions of $40 \mathrm{~m}, 143 \mathrm{~m}$, $223 \mathrm{~m}, 518 \mathrm{~m}, 762 \mathrm{~m}, 1000 \mathrm{~m}, 1250 \mathrm{~m}$, and $1503 \mathrm{~m}$. The field data acquisition is shown in Figure 11.

According to the field measurement results and the conclusion of numerical simulation analysis, the most representative members of the upper, middle, and lower layers are selected for analysis. In other words, the members with the maximum stress of corner columns, vertical supporting bars, and diagonal supporting bars in the upper, middle, and lower parts are selected for comparison, as shown in Figure 12

As shown in Figure 12, the stress variation law of bars in the field measurement is consistent with that of simulation results. The stress of bars increases with the increase of shaft sinking depth, and the measured value is less than the theoretical value in the simulation calculation. Therefore, the bar stress of the headframe is far less than the maximum bearing capacity of the bar within $1503 \mathrm{~m}$ of shaft sinking depth. In other words, these bars meet the design requirements and are in the elastic stress stage, and the instability failure of headframe members will not occur. Besides, with the increase of the shaft sinking depth, the measured stress value of the bars is gradually close to the simulated value. At the shaft sinking depth of $1503 \mathrm{~m}$, the measured stress value of the bars is basically consistent with the simulated value. It can be concluded that the simulation results can better reflect the actual situation. 


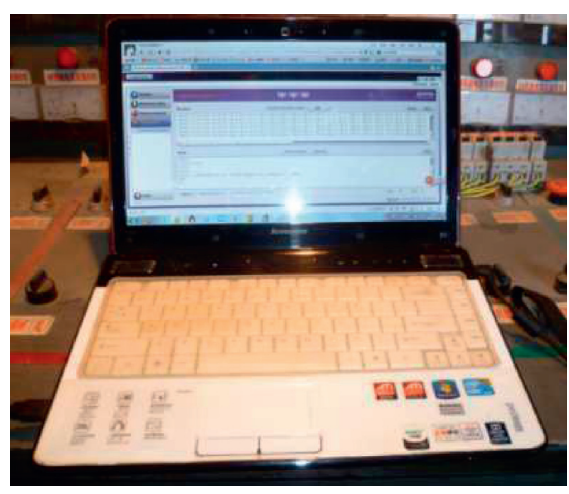

(a)

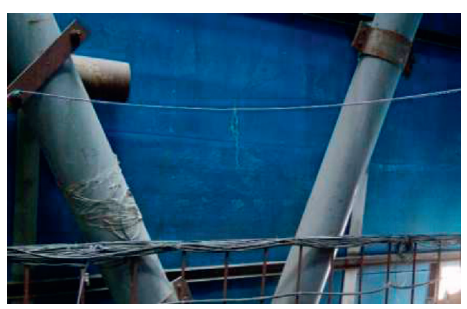

(d)

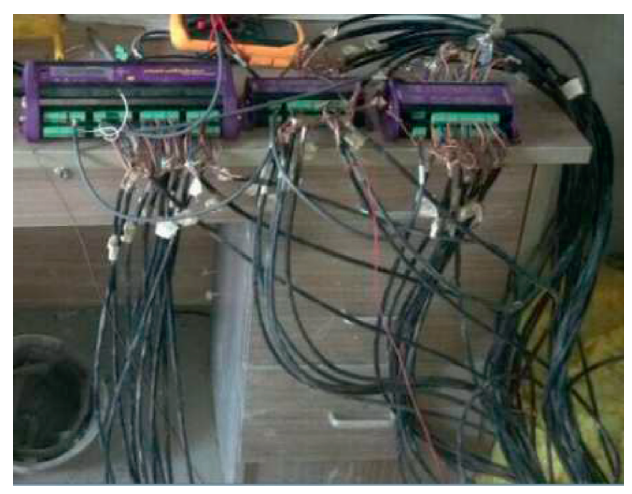

(b)

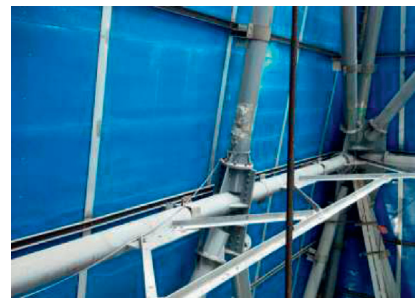

(c)

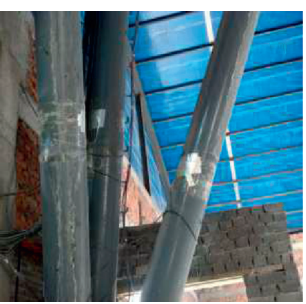

(e)

FIGURE 11: Field data acquisition. (a) Data acquisition equipment. (b) Datataker data acquisition. (c) Site map of upper measuring points. (d) Site map of middle measuring points. (e) Site map of lower measuring points.

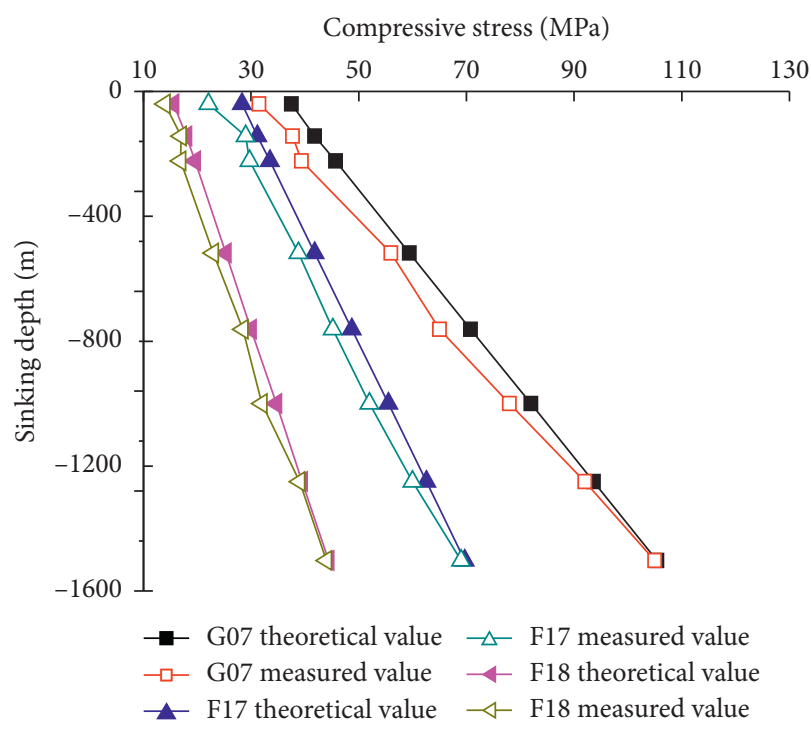

(a)

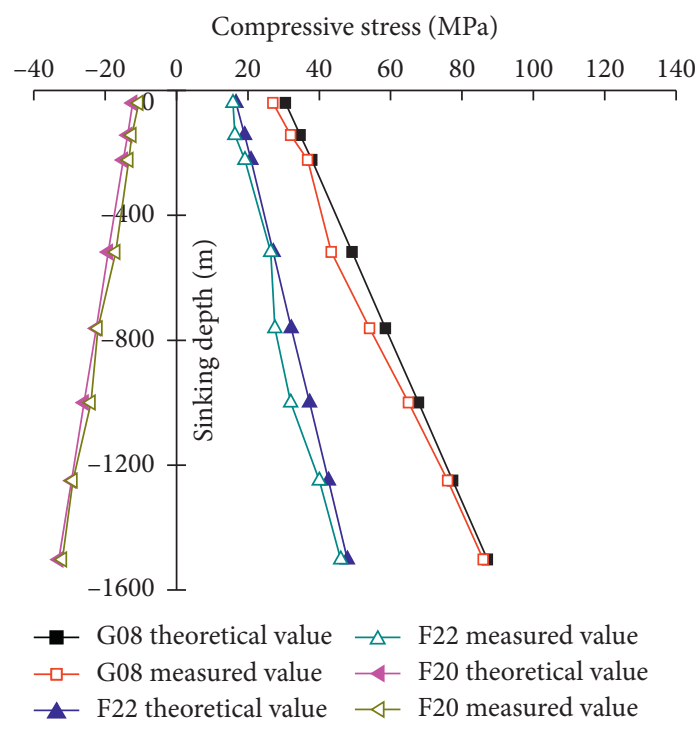

(b)

FIGURE 12: Continued. 


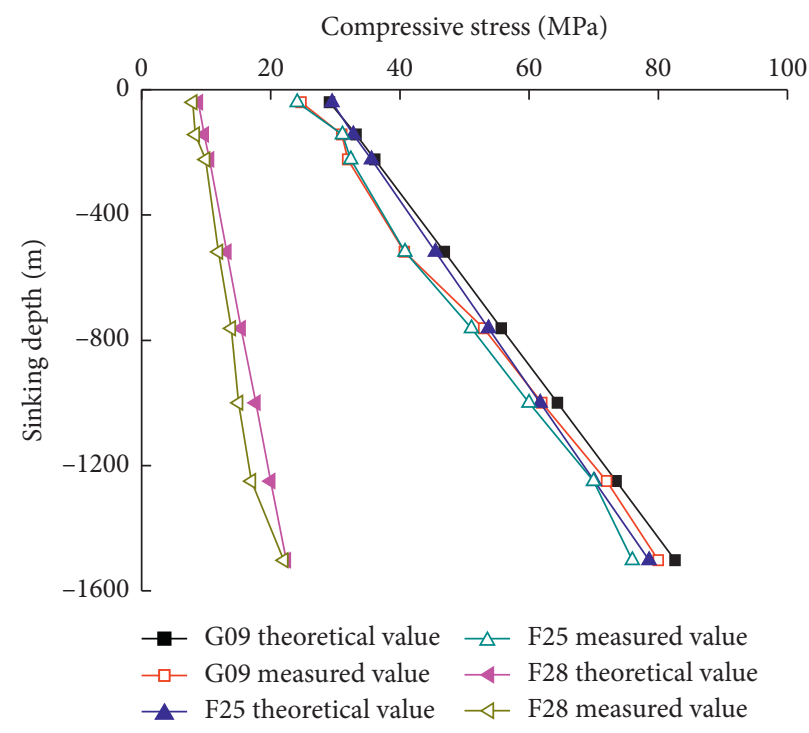

(c)

FIGURE 12: Comparison between measured values and theoretical values. (a) Upper members. (b) Middle members. (c) Lower members.

\section{Analysis of the Influence of Different Constraint Modes on the Support End}

The upper members mainly include corner column and supporting bar. According to the above simulation analysis and field measurement results, the top corner column G07, vertical supporting bars F17, and inclined supporting bars F18 are the most stressed. The stress variation curve of the upper member and the sheave wheel platform under different restraint modes with the shaft sinking depth is shown in Figure 13.

It can be seen that when the constraint of member changes from flexible to rigid, the slope of curves increases gradually. Within a certain range of sinking depth, the compressive stress of the flexible constraint has a greater change. Since the different constraint methods lead to different stress characteristics of the bar, the flexible constraint has a greater impact on the compressive stress of the bar.

As shown in Figure 13, the measured analysis results of the working state of the upper member are between the calculation results of the finite element numerical simulation of the rigid connection and the flexible connection. The corner column stress of the rigid connection at the end of the supporting bar is $55.7 \%$ lower than that of the flexible connection at the end of the supporting bar, and the supporting bar stress of the rigid connection at the end of the supporting bar is $36.17 \%$ and $58.3 \%$ higher than that of the flexible connection at the end of the supporting bar, respectively. It shows that the end-restraint mode of the supporting member has a great influence on the force of the uppermost member. Therefore, in the finite element numerical simulation, the determination of the end-restraint mode of supporting bars is particularly important for the calculation analysis and optimization design of the headframe in the large shaft sinking.

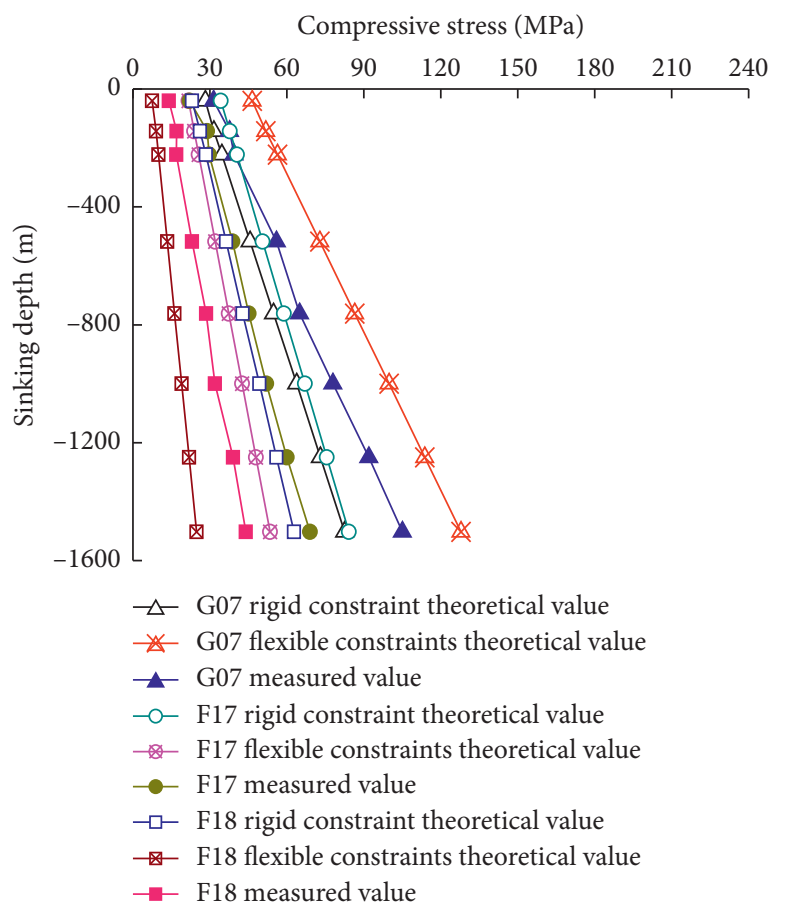

FIGURE 13: Variation curve of member stress with sinking depth under different restraint modes.

\section{Conclusions}

Aiming at the field application of the newly developed steel headframe for the superlarge and ultradeep shaft in the auxiliary shaft of the Sishanling iron mine, the working state and mechanical performance analysis of the headframe are carried out in combination with the actual project. The results of field measurement and finite element numerical 
simulation are compared and analyzed. The conclusions are drawn as follows:

(1) Numerical simulation analysis of the headframe members in eight sinking depths of $40 \mathrm{~m}, 143 \mathrm{~m}$, $223 \mathrm{~m}, 518 \mathrm{~m}, 762 \mathrm{~m}, 1000 \mathrm{~m}, 1250 \mathrm{~m}$, and $1503 \mathrm{~m}$ is performed. The results show that the stress of headframe members increases linearly with the increase of sinking depth;

(2) The measured stress of headframe in the on-site working condition is less than the theoretical stress of headframe in the finite element numerical simulation. When the sinking depth is less than $1503 \mathrm{~m}$, the reliability of this project is verified by the results of numerical simulation results and field measurement, that is, the headframe members are in the elastic stress stage, meeting the design requirements, and the instability failure of headframe members will not occur under the normal working condition within the sinking depth of $1503 \mathrm{~m}$.

(3) The end restraint mode of the supporting member has a great influence on the force of the top member. The reasonable selection of the end-restraint mode in the simulation is the key to the accuracy of the calculation results.

The numerical simulation in this study can better reflect the stress state of the shaft headframe in the actual project and provide a reliable guarantee for the follow-up mining work. The simulation results and measured results show that the internal force of the member bar has a large surplus, and the bar can be optimized to achieve the purpose of saving steel, which will be further studied.

\section{Data Availability}

The data used to support the findings of this study are included within the article.

\section{Conflicts of Interest}

The authors declare that they have no conflicts of interest.

\section{Acknowledgments}

This research was funded by the Tangshan Science and Technology Research and Development Plan (the Third Batch) Project of China (grant no.20150221C) and the Natural Science Foundation of the Jiangsu Higher Education Institutions of China (grant no. 20KJB560009).

\section{References}

[1] H. Z. Zhao, X. Zhen, and M. J. Li, "Development status of open-pit coal mines in China," China Mining Magazine, vol. 25, no. 6, pp. 12-15, 2016.

[2] H. Zhang, "Open-pit coal mine mining theory, technology and development trend," Opencast Mining Technology, vol. 34, no. 1, pp. 1-9, 2019.
[3] J. I. Rojas-Sola and I. Palomares-Munoz, "3d modelling and static analysis of a Spanish articulated metal headframe for mineral extraction," Dyna, vol. 90, no. 6, p. 602, 2015.

[4] D. Ma, J. Zhang, H. Duan et al., "Reutilization of gangue wastes in underground backfilling mining: overburden aquifer protection," Chemosphere, vol. 264, no. 1, p. 128400 , 2021.

[5] E. Rusiński, P. Moczko, and P. Odyjas, "Estimating the remaining operating time of mining headframe with consideration of its current technical condition," Procedia Engineering, vol. 57, pp. 958-966, 2013.

[6] A. Nechitailo, Y. Horokhov, and V. Kushchenko, "Analysis of the mode of deformation of the sub-pulley structures on shaft sloping headgear structures," in Proceedings of the 18th International Conference on the Application of Computer Science and Mathematics in Architecture and Civil Engineering, Istanbul, Turkey, June 2012.

[7] V. Kushchenko and A. Nechitailo, "The analysis of the intense deformed condition of the basic bearing elements of frame mowing mine headgears," Metal Constructions, vol. 17, no. 3, pp. 151-165, 2011.

[8] D. Ma, H. Duan, W. Liu, X. Ma, and M. Tao, "Water-sediment two-phase flow inrush hazard in rock fractures of overburden strata during coal mining," Mine Water and the Environment, vol. 39, no. 2, pp. 308-319, 2020.

[9] V. Kushchenko and A. Nechitailo, "Computer simulation of the stress-strain state of the subsurface stitched mine frame structures," Building Materials Science. Engineering Series: Computer Systems and Information Technology in Education, Science and Management, vol. 23, no. 78, pp. 155-159, 2014.

[10] E. G. Kassikhina, V. V. Pershin, and V. M. Volkov, "Assembling of steel angle headframe of multifunctional purpose. IOP conference series: materials science and engineering," IOP Publishing, vol. 253, no. 1, Article ID 012020, 2017.

[11] D. Ma, H. Duan, Q. Zhang et al., "A numerical gas fracturing model of coupled thermal, flowing and mechanical effects," Computers, Materials \& Continua, vol. 65, no. 3, pp. 21232141, 2020.

[12] Y.-B. Wang, G.-Q. Li, S.-W. Chen, and F.-F. Sun, "Experimental and numerical study on the behavior of axially compressed high strength steel box-columns," Engineering Structures, vol. 58, pp. 79-91, 2014.

[13] T.-J. Li, S.-W. Liu, G.-Q. Li, S.-L. Chan, and Y.-B. Wang, "Behavior of Q690 high-strength steel columns: Part 2: parametric study and design recommendations," Journal of Constructional Steel Research, vol. 122, pp. 379-394, 2016.

[14] N. E. Shanmugam, S. P. Chiew, and S. L. Lee, "Strength of thin-walled square steel box columns," Journal of Structural Engineering, vol. 113, no. 4, pp. 818-831, 1987.

[15] C. S. Stolle and J. D. Reid, "Development of a wire rope model for cable guardrail simulation," International Journal of Crashworthiness, vol. 16, no. 3, pp. 331-341, 2011.

[16] O. Hasançebi and S. Carbas, "Bat inspired algorithm for discrete size optimization of steel frames," Advances in Engineering Software, vol. 67, pp. 173-185, 2014.

[17] D. Ma, H. Duan, J. Liu, X. Li, and Z. Zhou, "The role of gangue on the mitigation of mining-induced hazards and environmental pollution: an experimental investigation," Science of the Total Environment, vol. 664, pp. 436-448, 2019.

[18] M. Hartnett and P. Mitchell, "An analysis of the effects of the leg-spacing on spectral response of offshore structures," Advances in Engineering Software, vol. 31, no. 12, pp. 991-998, 2000. 
[19] E. Dogan and M. P. Saka, "Optimum design of unbraced steel frames to LRFD-AISC using particle swarm optimization," Advances in Engineering Software, no. 1, pp. 27-34, 2012.

[20] V. Kushchenko and A. Nechitailo, "Analysis of the mode of deformation of the joints of guide pulley resting on shaft sloping headgear structures," Metal Constructions, vol. 18, no. 2, pp. 97-109, 2012.

[21] K. Kuzniar and T. Tatara, "Dynamic investigations of various civil engineering structures due to ambient and mining tremors," EDP Sciences, vol. 24, Article ID 04008, 2015.

[22] V. Kushchenko and A. E. Nechitailo, "Strength analysis of the nodes of the bearing of the guide pulleys of frame ukosny mine pile drivers," Metal Constructions, vol. 20, no. 1, pp. 15-27, 2014.

[23] S. Sandun De Silva and D. P. Thambiratnam, "Dynamic characteristics of steel-deck composite floors under humaninduced loads," Computers \& Structures, vol. 87, no. 17-18, pp. 1067-1076, 2009.

[24] V. Kushchenko and A. E. Nechitailo, "Factor analysis of the stress state of the support units of the guide pulleys of the frame shaft copers," Construction Materials Engineering. Series: Life Safety, vol. 71, no. 2, pp. 92-101, 2013.

[25] V. Kushchenko and A. E. Nechitailo, "Rational design of bearing units for guide pulleys," Budivelne Virobnitstvo, vol. 57, no. 2, pp. 42-45, 2014.

[26] S. Mustafa, "Artificial Bee Colony algorithm for optimization of truss structures," Applied Soft Computing, vol. 11, no. 2, pp. 2406-2418, 2011.

[27] D. Ma, J. Wang, X. Cai et al., "Effects of height/diameter ratio on failure and damage properties of granite under coupled bending and splitting deformation," Engineering Fracture Mechanics, vol. 220, p. 106640, 2019.

[28] D. Kong, "Unilateral sprag-type vertical shaft headframe rectification process," China Coal, vol. 39, no. 4, pp. 71-73, 2013.

[29] Q. F. Xiao, M. Li, and B. G. Chen, "Freezing mine shaft headframe differential settlement," Mine Onstruction Technology, vol. 30, no. 4, pp. 37-39, 2009.

[30] H. L. Zhang, W. F. Jia, and Z. L. Chen, "Application research of grouting reinforcing shaft headframe," Modernization of Coal Mines, vol. 22, no. 2, pp. 7-9, 2016.

[31] C. Y. Zhang, W. H. Zheng, and X. M. Feng, "Research on the deformation monitoring method of a derrick," Geomatics and Spatial Information Technology, vol. 39, no. 3, pp. 202-204, 2016.

[32] D. Ma, H. Duan, X. Li, Z. Li, Z. Zhou, and T. Li, "Effects of seepage-induced erosion on nonlinear hydraulic properties of broken red sandstones," Tunnelling and Underground Space Technology, vol. 91, p. 102993, 2019.

[33] Z. Q. Wang, G. Y. Wang, W. H. Zhang, S. J. Zhang, Y. L. Ren, and Z. Q. Liu, "Analysis and forecast of shaft frame inclination and its rectification control," Metal Mine, vol. 31, no. 4, pp. 24-26, 2002.

[34] V. Gusella, O. Spadaccini, and A. Vignoli, "Dynamic identification of vega platform drilling derrick," in Proceedings of the Second International Offshore and Polar Engineering Conference, pp. 314-321, June 1992, San Francisco, CA, USA.

[35] M. Link, "Updating of analytical models - review of numerical procedures and application aspects," Structural Dynamics, vol. 2001, 2000.

[36] Z. Q. Li and H. W. Li, "Structural optimization of mine hoist derrick based on ANSYS," Coal Mine Machinery, vol. 37, no. 6, pp. 18-20, 2016.

[37] P. B. Xu, "Study on analysis of virtual fatigue life of two-pillar mask hydraulic support," Coal Mine Machinery, vol. 40, no. 3, pp. 34-36, 2019.
[38] D. Ma, J. J. Wang, and Z. H. Li, "Effect of particle erosion on mining-induced water inrush hazard of karst collapse pillar," Environmental Science and Pollution Research, vol. 26, no. 19, pp. 19719-19728, 2019.

[39] D. Ma, X. Miao, H. Bai et al., "Impact of particle transfer on flow properties of crushed mudstones," Environmental Earth Sciences, vol. 75, no. 7, p. 593, 2016. 